\title{
What provokes Opra - how to avoid the worst
}

Received: 18th July, 2000

\section{John Hayes CBE}

a solicitor by training, was appointed Chairman of Occupational Pensions Regulatory Authority (Opra) in April 1996 and took up the appointment on a full-time basis in June 1996. He was formerly Secretary General of the Law Society for nine years.

\begin{abstract}
This paper sets out Opra's principles as regards investigations, criminal prosecutions and civil offences and details the recommended course of action to take. The paper is based on the author's presentation made at the Henry Stewart Conference on 'Pensions Compliance' on 18th July, 2000 in London.
\end{abstract}

Keywords: Opra; investigations; criminal prosecutions; civil offences

\section{Investigations}

It should be made clear that the Board of Opra does not control investigations, because if it did so, it might be regarded as unable to give a fair verdict on the facts presented to it. What is written here therefore is not based on first-hand experience, although the Board does comment from time to time, on how well or badly it perceives that any particular investigation has been done. As Board members, sitting in committee, to deal with an individual case, we are not always told what triggered an investigation, but a glance at the published material would give a useful clue to how cases get off the ground.

The author would mention these sources:

- reports from statutory whistleblowers such as scheme auditors or scheme actuaries

(Opra, Invicta House,

Trafalgar Place, Brighton BN1 4DW.

Tel: 01273627 610; Fax: 01273627 760)
- trustees themselves voluntarily or under a duty, for example in relation to late payments
- reports from other regulators and enforcement agencies, including the police and the Inland Revenue

- reports in the media; reports from other advisers including lawyers although not normally because of professional privilege, from the client's own lawyer

- insurance companies and administrators

- Pensions Ombudsman and OPAS.

Some of these bodies will have statutory or internal requirements, which have to be satisfied before a report can be made to Opra.

\section{Dealing with the paperwork at the outset}

A fully trained regulatory officer, normally with a background in investigation, not necessarily in pensions, may have a caseload approaching 200 cases. To keep this volume down, there is a screening process designed to ensure 
that those cases that are unlikely to require full investigation are dealt with elsewhere. The screening unit will customarily check the Opra database to ascertain what is already known about the particular scheme; in the light of this and the nature of the report received, a decision will be taken as to whether merely to note the report, possibly issue a warning letter, or whether to generate more specific enquiries.

Most requests for information which will not be contained in a statutory notice, will be merely to seek information about the scheme, where it is not already held, and/or to seek further reassurance that the breach in question has now been remedied. On this basis anything up to 1,000 cases a month may be closed. What could trigger further regulatory interest, leading to escalating the case to the level of a regulatory officer, will be apparent indifference to further reminders sent to the scheme or individual concern. Managers check, on a sample basis, where a particular case appears to be going nowhere with no apparent activity on either side. The first answer, therefore, to the question of avoiding Opra's wrath is to reply in a timely way to the questions Opra asks.

Avoiding the issue, therefore, by not replying to Opra is bound to increase the ultimate problem rather than reduce it. Opra staff use the telephone to enquire or chase up queries, but again failure to return a call will tend to accentuate interest in a case rather than reduce it.

\section{More formal steps in an investigation}

Most requests for information are informal, that is, they do not invoke a specific statutory power, where failure to respond is itself an offence, but if this approach does not seem to be working, or sometimes in other quite exceptional circumstances, a notice may be issued under section 98 of the Pensions Act, requiring the production of documents. If this stage is reached, almost certainly an Opra regulatory lawyer will vet the notice before it is sent. Such notices are not sent lightly. Even before having to be tested against any challenge under the Human Rights Act, the question will be asked whether it would have been possible to have used more informal means. Usually, however, these have been tried before the formal notice is sent. A period is allowed for producing the documents, which is sufficiently long, in the ordinary course of business for people to be able to produce those documents. If an extension is sought, it is far better to do so before the time has elapsed than afterwards.

Should there be some doubt in the mind of the person to whom the notice is sent, or their advisers about its lawfulness, which is conveyed to Opra, then the regulatory officer and lawyer will consider whether it would be sensible to allow more time. Regulatory lawyers are happy to talk to their opposite numbers.

From what the author is able to observe from the cases that have reached Opra, it seems to be the policy, derived from the Act, to ensure that these notices are sent to the person who in day-to-day terms, within an organisation, actually has the control over the relevant documents or knows most precisely where they may be obtained.

Such a formal notice will normally be issued by recorded delivery or another similar system. It is important that organisations do have arrangements for opening the post for people who are not there at the time. Even though the company itself may not be liable to be prosecuted, if the notice is issued against 
an individual, the reputation of an organisation is at stake if there is no apparent system for checking whether correspondence has been received and dealt with appropriately. Opra also has the power to visit premises, carry out an examination, and obtain a relevant document. There is limited power to ask for information relevant to finding the relevant documents; there is no power to visit premises which are used solely as a private dwelling house rather than in whole or in part of the purposes of a trade or business. Again, because it might be alleged that such an inspection was an infringement of human rights relating to property or possessions, a lawyer's advice will be sought first before such an inspection is authorised by a regulatory director. The rules about selfincrimination which are part of domestic law, as well as enshrined in the European Convention, have to be observed.

Section 100 of the Pensions Act 1995 allows an application to be made for a warrant, on the grounds set out in that section, all of which bear on apparent breaches or the possibility that a document would effectively disappear if the warrant was not executed. Again, internally there is a procedure under which a lawyer will be consulted. On one occasion, the lawyer actually asked the court for the warrant.

Again, human rights legislation bites because the execution of a warrant is clearly far more intrusive than merely writing to ask for a document or visiting premises and entering them with the occupiers' consent.

\section{Criminal prosecutions}

Almost inevitably inspectors from Opra will interview the possible defendants and also relevant witnesses. Almost all of the cases that have been seen at Board level for possible prosecution have not involved a lawyer being present at the interview on behalf of the defendant, although the defendant is entitled to bring one. In many cases, however, the person has already consulted a lawyer and been advised on how generally to deal with the interview. As a member of the prosecution committee, the author can say that Opra regards the transcript of these interviews as very important in establishing whether the defendant appears to admit the offence, but also whether there seems to be some strong mitigating factors which might make it sensible to consider issuing a caution rather than going for a full-blown prosecution, or even deciding to pursue no sanction.

From this perspective, the more open the defendant is, either at the interview or subsequently, the better. However, there are limitations on what information can be used by a prosecution where someone has not been formally cautioned. Phrases at the end of the interview transcript, saying that the defendant declined to say anything further, is not taken by Opra as a sign that the interviewee was deliberately less than candid. It may have been little more than an expression of relief that the interview was over.

As a lawyer, but not one who has often had to act for the defence, the author believes that it makes good sense for the defendant, after being interviewed, to consider carefully whether it might be worth writing a letter to Opra with the request that the letter be shown to the Board committee which will deal with the matter. The Code of Practice for Crown Prosecutors indicates a number of factors which may need to be taken into account in deciding whether the public interest requires there to be a prosecution. If the lawyer should consider that their client is unlikely to have a credible defence, then 
a letter from him or her, which does not seek to minimise the fact that an offence has been committed and that the defendant is responsible for it, may however helpfully guide the committee when it comes to deal with the issues of public interest.

There have been one or two such cases, but more often if this is done, it is after Opra has notified the parties that the Chief Executive has been authorised to consider the possibility of bringing a criminal prosecution.

Unlike civil submissions, the papers which the regulatory officer prepares for the committee are not sent to the potential defendant or their advisers. This is because the ultimate determiner of the guilt of the defendant and the penalty is the court, rather than Opra. Advanced disclosure rules mean that the defendant and his advisers will have the opportunity to see relevant papers before the case is heard. The code, as used within Opra, operates to remind members of the prosecution committee that if the defendant or his adviser should put forward some mitigation then the committee should consider it even if the summons may already have been issued. The Board committee leaves it entirely for the Chief Executive after considering appropriate legal advice external or internal, whether to proceed in the light of the evidence. It is the public interest matters which are retained for decision by the relevant prosecution committee.

There was a case where a firm of professional trustees was being prosecuted for the failure to produce accounts on time. After the prosecution was authorised, a full submission was made by their advisers. While the submission itself did not say precisely what steps had now been taken to prevent a recurrence in the future, when Opra asked for this, it was sufficiently convinced by their good intentions, that knowing what had gone on before with the particular insurer, that Opra felt justified in asking for the prosecution to be withdrawn and the issue of a caution instead.

\section{Civil offences}

There are now three categories of these:

— full-blown submission

— shortform submission

- emergency application.

In a full-blown submission, the determination committee will receive exactly what the defendant receives, namely a summary and chronology of the case, copies of all the relevant documents, including transcripts of interviews, as well as any further submissions made by the defendants or any other interested party to whom the initial submission has been sent.

Frequently, the submission document is made heavier because Opra has extracted the whole of the trust document, although it is relatively rare that it has to refer to more than a few clauses in it. The author tends to look first of all at the submission made by the defence, because it is there that one learns whether the offences are admitted. Opra is conscious, however, that people could conceivably plead guilty to offences of which they are not actually guilty, for example, because we conclude that they were not trustees or that a breach which they are charged with, was not relevant or in force at the particular time the offence was alleged to have been committed. The lawyers in the secretariat check such matters before the Board meet.

At a determination committee, apart from the Board members, it is only the Board lawyer and secretariat who are 
present together in an observer capacity only, with the relevant regulatory director.

The most impressive mitigation is that which makes no bones about the commission of the offence, does not immediately try to lay the blame on others, very properly seeks to put the offence in context, but concentrates in detail on what is being done to prevent a recurrence in the future.

\section{Shortform submissions}

These have been introduced for the new civil offences relating to late payments and late accounts. They consist normally of a single sheet of paper giving the names of the relevant scheme, employer/trustees, going on, in summary form, to describe the offence, eg, the accounting year, the date that accounts should have been audited to comply with the relevant law and the date, if any, when the accounts were finally completed and audited. For a late payments case, the Board will be told how much had been deducted that month from the employees wages, when it should have been received, and when it was actually received. In addition, any response from the potential defendants is attached.

These powers have now been used on a number of occasions. At the time of writing, the fines have included a fine of $£ 100$ per trustee where the accounts seem to have been outstanding for around three months. Fines of $£, 50$ have been applied in generally late payment cases with $\mathcal{K}^{25}$ in others and a warning in one other.

At this stage, the results seem encouraging in that where fines have been imposed, there has been ready acknowledgment of the default and cheques received rather than reviews requested.

\section{Emergency application}

Occasionally circumstances arise where there is an ongoing investigation into usually a series of alleged breaches, but where it is considered that there is a prospect that the relevant assets will be moved or wasted, if action is not taken. Under those circumstances, regulatory staff are authorised to make an emergency submission to a Board determination committee, usually for the appointment of an independent trustee to hold the position, usually to the exclusion of the other trustees. Board staff have been advised now that if those circumstances should change, then rather than continue to incur costs, submissions should be made to the Board for terminating the appointment, possibly preceded by a more informal indication to the trustees so that costs are not further incurred.

Reviews of such decisions are automatically granted, because unlike the normal civil submission, the people affected have not had the opportunity to put their case when the determination committee first makes a decision.

\section{Conclusion}

The practices described here may be changed from time to time or adapted to suit a particular case. However, the principles are clear. These are that the Board does not become involved in investigation, in case this taints its role in subsequent adjudications.

In addition, statutory powers are only used where there appears to be good reason to use them and that lawyers and senior managers are normally involved before those powers are exercised. With the incorporation of the European Convention on Human Rights, it will be even more necessary to be able to show that the processes both in general and as 
applied in individual cases, are fair, reasonable and proportionate.

Opra sees its powers as basically concerned with ensuring compliance, being primarily preventative rather than punitive, informal means being used wherever possible and with as little fuss as possible. It is to be hoped that regime can survive both the Human Rights Act and the Freedom of Information Act. 